\title{
Isolation of Candida species in children and their biofilm-forming ability on nano-composite surfaces
}

Harina Akila Che Hussin ${ }^{1}$, Nadiah Arshad ${ }^{1}$, Siti Nor Humaira Nor Azemi ${ }^{1}$, Raja Izzatun Nisa' Raja Sahrul Hishan ${ }^{1}$, Wan Nur Fatihah Wan Mohd Kamaluddin², Nurul Alia Risma Rismayuddin ${ }^{2}$, Mohd Haikal Mohd Halil ${ }^{3}$, Ahmad Faisal Ismail ${ }^{4}$, Fatimah Maryam Ali $^{1}$, Mohd Hafiz Arzmi ${ }^{*}$

\author{
${ }^{1}$ Department of Fundamental Dental and Medical Sciences, Kulliyyah of Dentistry, International \\ Islamic University Malaysia, Kuantan, Pahang, Malaysia. \\ ${ }^{2}$ Kulliyyah of Nursing, International Islamic University Malaysia, Kuantan, Pahang, Malaysia. \\ ${ }^{3}$ Department of Restorative Dentistry, Kulliyyah of Dentistry, International Islamic University Malaysia, \\ Kuantan, Pahang, Malaysia. \\ ${ }^{4}$ Department of Paediatric Dentistry and Dental Public Health, Kulliyyah of Dentistry, International \\ Islamic University Malaysia, Kuantan, Pahang, Malaysia
}

\begin{abstract}
Candida species including Candida albicans, Candida krusei and Candida glabrata are opportunistic microorganisms that inhabit oral cavity. The objective of this study is to determine the effect of dental caries on Candida spp. biofilm-forming ability on nanocomposite with the hypothesis that dental caries enhances the colonization of Candida spp. To assess Candida spp. colonisation in the oral cavity of the paediatric patient, samples were obtained from 30 subjects aged five to six years old from Kuantan, Pahang, Malaysia. The samples were collected from buccal mucosa, palate and tooth surfaces using sterile swabs. $10 \mathrm{~mL}$ of patient's saliva suspension was also collected. Following that, the samples were inoculated on CHROMagar and incubated for $24 \mathrm{~h}$ at $37^{\circ} \mathrm{C}$. Candida biofilm of caries isolate C. albicans (HNFC2), and C. albicans ATCC 32354 were developed on three different types of nano-composites. The study showed that no $C$. albicans was isolated from the caries-free oral cavity while $76 \%$ of children with caries possessed Candida spp. $65 \%$ of the yeasts were isolated from the tooth surface. Only $35 \%$ of the total isolates were obtained from soft tissues, including palatal and buccal mucosa. C. albicans is the most isolated Candida spp. with $82 \%$ and $67 \%$ of the yeast were obtained from the tooth surface and buccal mucosa, respectively. Besides, HNFC2 significantly colonised the nanocomposites more than the ATCC $(P<0.05)$. In the comparison of the three types of nanocomposites, nano-hybrid-based containing pre-polymerised filler (cB) exhibited the least $C$. albicans HNFC2 cells colonisation with $7.7 \times 10^{3}$ cells $\mathrm{mL}^{-1}$. In contrast, the nano-composite that contained bulk-filled nanohybrid $(\mathrm{cC})$ was the most colonised with $14.3 \times 10^{3}$ cells $\mathrm{mL}^{-1}$. In conclusion, dental caries enhances the colonization of Candida spp. in children's oral cavity, and that caries isolate form more biofilm on nano-composites compared to the lab strain C. albicans.
\end{abstract}

Keywords: Paediatric, dental caries, Candida species, biofilm formation, nano-composite

${ }^{*}$ Corresponding Author:

Telephone: +6013-260 1445

Email: hafizarzmi@iium.edu.my 


\section{Introduction}

Oral microbiome exists in both planktonic and biofilm (plaque) forms (Kolenbrander et al., 2010). More than 2000 groups of pathogens present in the oral cavity with opportunistic pathogens encompass a substantial number of them. These opportunistic pathogens have been shown to involve in the establishment of several oral or systemic disease (Dewhirst et al., 2010; Warinner et al., 2014). Currently, the categorization of this microbiome is based on shotgun metagenomics and comparative 16S rRNA gene sequencing. Formerly, they were divided according to simple sugar fermentation, their morphology and chemical contents (Chaffin, 2008; Donovan et al., 2018).

Candida is a yeast that belongs to the kingdom fungi. It is known as imperfect fungi within the family of Cryptococcaceae (Rybalkin et al., 2014). It has sizes ranged from two to five micrometre, and it also can be presented in hyphae and yeast form (Samarayanake, 2002; Rós Ásmundsdóttir et al., 2008). A few types of Candida spp. for instance, C. albicans and Candida dubliniensis have aptitude in septate hyphae formation. This ability is essential during pathophysiology of disease as Candida spp. in hyphae form is more active in tissue invasion and more capable of injuring the invaded tissue (Samaranayake, 2006; Sudbery, 2011).

Candida spp. are part of a healthy microbiome. There are 200 recognized species in the genus of Candida with seven species are reported to play an essential role in pathogenesis of human diseases including $C$. albicans, Candida kefyr, C. glabrata, C. krusei, Candida parapsilosis, C. dubliniensis and Candida stellatoidea (Samarayanake, 2002; Rós Ásmundsdóttir et al., 2008; Sida et al., 2016). Among all these Candida spp., C. albicans has been testified to be the most predominant in the oral cavity (Akdeniz et al., 2002; Nejad et al., 2013). Virulence factors of Candida vary between species, and they include the phenotypic switching ability, hydrophobic cell surface, biofilm formation as well as hydrolytic enzymes, candidalysin and quorum sensing molecules production (Haynes, 2001; Williams et al., 2011; Arzmi et al., 2012; Arzmi et al., 2014; Kragelund et al., 2016; Sida et al., 2016).

Candida spp. mainly $C$. albicans is one of the causes of many harmful diseases, including oral candidiasis and oral squamous cell carcinoma (Arzmi et al., 2018). C. albicans is a normal commensal of the human body and causes no damage. However, when the host defences are weakened, it is capable of becoming pathogenic and causing severe problems (Ramirez-Garcia et al., 2013). C. albicans is an innocuous dimorphic fungus. However, it can become pathogenic and harmful when the balance of microbial flora has been disturbed, or immune system of the host has been debilitated (Zunt, 2000; Byadarahally Raju et al., 2011).

A study conducted in Singapore showed that $C$. albicans was the most prevalent species isolated from the blood of disease-ridden patients. Aside from $C$. albicans, C. tropicalis, C. glabrata $C$. parapsilosis, and C. krusei were also reported to be isolated from the subjects. Besides that, $C$. albicans was frequently found in the paediatric patient, too (Yang et al., 2003; Pereira et al., 2010). Besides, a retrospective study conducted in Lyon, France from 1998 to 2001 revealed that candidal infection was mainly caused by C. albicans $(49.5 \%)$ and followed by $C$. glabrata with $12.6 \%$ and C. parapsilosis with $12.1 \%$. The same study also showed that in onco-haematology patients, candidemia was majority caused by $C$. krusei and C. albicans (Martin et al., 2005). A study in Malaysia has discovered that the most dominant Candida spp. isolated from the bloodstream was $C$. albicans (44.2\%). They were also able to isolate other Candida spp. aside from $C$. 
albicans such as C. parapsilosis (26.0\%) and C. tropicalis (17.7\%) (Ng et al.,1999).

Nano-composite has become the choice of dental practitioners in modern dentistry to replace other restorative materials such as amalgam due to a better aesthetics quality and abrasion resistance (Cramer et al., 2011). Furthermore, in combination with good bonding, nanocomposite presents adhesive properties which can preserve the tooth structure during cavity preparation which is not possible with amalgam restoration (Correa et al., 2012). In order to improve its mechanical and physical properties, conventional composite has been improved by incorporating different compositions that possess different properties (Burgers et al., 2009).

The objective of this study is to determine the effect of dental caries on Candida spp. biofilm-forming ability on nano-composites with the hypothesis that dental caries enhances the colonization of Candida species.

\section{Materials and Methods}

\section{Sample isolation}

Before the commencement of sample collection from children at International Islamic University Malaysia (IIUM) Dental Polyclinic and Adik Arif Kindergarten in Kuantan, Pahang, Malaysia, ethical approval (IREC 2018-172) was obtained from the IIUM Research Ethics Committee (IREC) on the $8^{\text {th }}$ May 2018.

Briefing regarding this study was given to the parents, and written consent was obtained before sample taking. The data was recorded on clinical examination sheet. A total of 30 healthy pre-schooled children (15 caries-free patients and 15 patients with caries) aged five to six years old consented by parents were included in the study. The exclusion criteria were children with co-morbidity and not consented by parents. The samples were collected in the presence of dental clinicians. The oral rinse technique was conducted to isolate microbial samples from the subject. In brief, patients were requested to have their mouth rinsed with $10 \mathrm{~mL}$ of sterile saline for one minute and spit in a sterile container. Following that, the surface of the teeth, palate and buccal mucosa were swabbed with a sterile swab, and the samples were transported immediately to the laboratory for identification of Candida spp.

\section{Identification of Candida species}

The samples that were previously collected from paediatric patients were inoculated onto Candida spp. selective CHROMagar (BD, USA) aseptically which was prepared beforehand for identification of Candida spp. Prior inoculation, each petri dish was divided into four parts and labelled with saliva suspension (S), tooth $(\mathrm{T})$, palate $(\mathrm{P})$ and buccal mucosa $(\mathrm{B})$. To identify Candida spp. from saliva suspension, the transport mediums which contain microbial isolates were vortexed vigorously using a vortex mixer (Biologix, Singapore) followed by inoculation on CHROMagar using sterile swabs.

Meanwhile, to identify Candida spp. from other oral sites, the collection swab which was used to collect the sample from the oral surfaces of children was swabbed on CHROMagar aseptically. The plates were incubated at $37 \stackrel{\circ}{\mathrm{C}}$ for 24 $\mathrm{h}$ to $48 \mathrm{~h}$, aerobically. The colour of the colony grown was recorded. The colony which exhibited green, dark pink and white were identified as C. albicans, C. krusei and $C$. glabrata, respectively. The species of Candida spp. were finally confirmed using API 20C AUX (Biomerieux, USA).

\section{Enumeration of Candida species from saline suspension}

The method by Alnuaimi et al. (2013) was conducted to enumerate the number of Candida spp. In brief, saliva suspension collected from the patient was vortexed vigorously. Later, $100 \mu \mathrm{L}$ of the 
suspension was serially diluted in $900 \mu \mathrm{L}$ sterile saline. Following that, $10 \mu \mathrm{L}$ of the diluted suspension was pipetted onto haemocytometer, and a clean glass coverslip was placed to secure the sample. Finally, the number of Candida spp. was enumerated by observing the haemocytometer under a light microscope (Olympus, Japan). The morphology of Candida spp. was also recorded based on the observation under the microscope.

\section{Identification of Candida species colony morphology}

To identify the colony morphology of Candida spp., a loopful of Candida spp. that was previously cultured on CHROMagar was inoculated onto a fresh CHROMagar using single dilution streaking method to obtain a single colony of Candida spp. Later, the plate was incubated for $24 \mathrm{~h}$ to $72 \mathrm{~h}$ at $37^{\circ} \mathrm{C}$, aerobically. Finally, the colony morphology, including margin, elevation and form, were observed and recorded.

\section{Preparation of nano-composite beads}

Three different types of nano-composites (cA, $\mathrm{cB}$ and $\mathrm{cC}$ ) as described in Table 1 were prepared using a round plastic mould (6 $\mathrm{mm}$ diameter $\times 5 \mathrm{~mm}$ height). Each bead was then polished beforehand. Following that, all nano-composites were sterilized using ultra-violet (UV) light radiation technique.

\section{Growth of Candida albicans}

C. albicans American Type Culture Collection (ATCC) 32354 was subcultured on yeast peptone dextrose (YPD) agar and incubated at $37{ }^{\circ} \mathrm{C}$ for $24 \mathrm{~h}$. Following that, a single colony of $C$. albicans was inoculated in YPD broth and standardized using a spectrophotometer to obtain an $O_{620 \mathrm{~nm}} 0.1$ that was equivalent to $10^{6}$ cells $\mathrm{mL}^{-1}$. Finally, the $1.5 \mathrm{~mL}$ of the suspension was aliquoted into $2 \mathrm{~mL}$ sterile Eppendorf tube and stored at $-20{ }^{\circ} \mathrm{C}$ (Figure 4). A similar protocol was repeated to grow $C$. albicans isolated from the oral cavity of children with caries (HNFC2).

\section{Static biofilm formation}

The study of static biofilm was conducted according to the modified protocol by Arzmi et al. (2016). Initially, $750 \mu \mathrm{L}$ of YPD broth was pipetted into each well of 12 -well plate. Following that $750 \mu \mathrm{L}$ of $C$. albicans suspension standardized at $10^{6}$ cells $\mathrm{mL}^{-1}$ in YPD broth was added in the same well. The suspension was mixed using a sterile pipette. Wells that contained only YPD broth were representing as the negative control. Finally, the sterile nano-composite bead was placed into each well aseptically, and the plate was incubated at $37^{\circ} \mathrm{C}$ for $24 \mathrm{~h}$.

\section{Enumeration of Candida albicans}

Following incubation, the growth medium was discarded, and each well was rinsed twice with $1 \mathrm{~mL}$ of sterile distilled water. Later, the nano-composite bead was transferred into a sterile $15-\mathrm{mL}$ tube containing $3 \mathrm{~mL}$ of sterile distilled water. The tube was sonicated using ultrasonicator (Amsonic, USA) for $60 \mathrm{~s}$. Finally, $10 \mu \mathrm{l}$ of the suspension was pipetted onto haemocytometer to measure the cell number (Alnuaimi et al., 2014). All protocols were repeated in three biological replicates to confirm reproducibility.

\section{Data analysis}

All data were statistically analysed using SPSS Statistic software version 25.0. Independent T-test was used to compare lab strain, and caries isolates $C$. albicans and analysis of variance (ANOVA) associated with post hoc Tukey test was used to compare three different nanocomposites. The data were considered statistically significant when $p<0.05$.

\section{Results}

\section{Colonization of Candida species in paediatric patients}

Our data showed no Candida spp. was isolated from caries-free children. 
However, $76 \%$ of the total samples from caries patients contained Candida spp. isolates (Figure 1). Of these, $65 \%$ of Candida spp. were isolated from the teeth while $18 \%$ were isolated from saliva suspension. Besides, $18 \%$ of the samples were also isolated from buccal mucosa (Figure 2). No C. albicans was isolated from the palate.

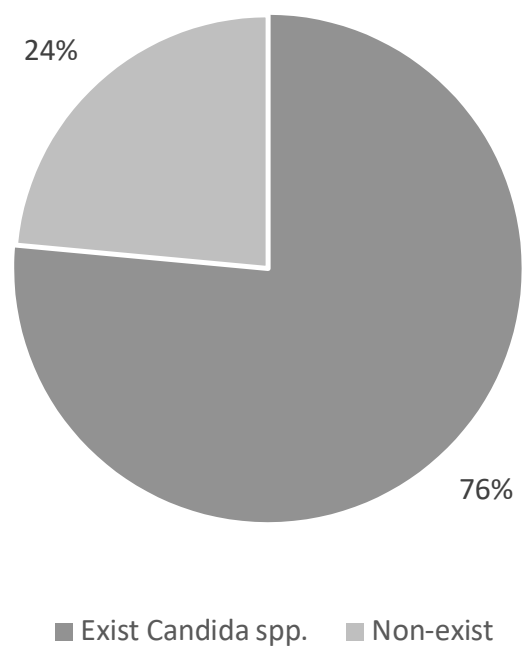

Figure 1. Percentage of caries children with Candida spp. ( $N=15)$.

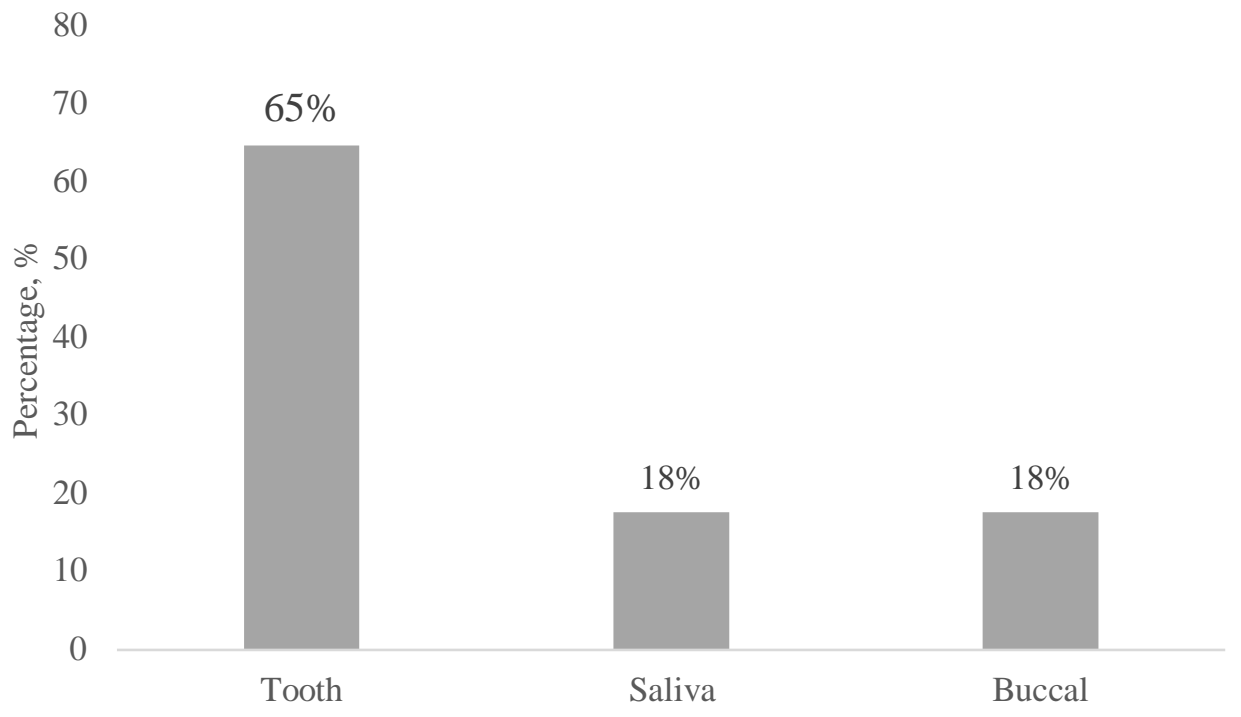

Figure 2. Percentage distribution of Candida spp. in children based on location; tooth, saliva and buccal mucosa of children with dental caries $(\mathrm{N}=15)$. No Candida spp. was isolated from palate. 
Distribution of $C$. albicans and non- $C$. albicans in the oral cavity of children with dental caries

Candida spp. were observed to colonise the tooth surface, saliva suspension and buccal mucosa of paediatric patients with dental caries. There were $82 \%$ of the samples isolated from tooth surface of caries patients exhibited as mono-species C. albicans, while $9 \%$ was non-C. albicans (Figure 3). There were only $9 \%$ of patients with dental caries possessed both
C. albicans and non-C. albicans in the tooth surface.

In addition, $67 \%$ of the paediatric patients with dental caries had mono-species $C$. albicans isolated on the buccal mucosa, whereas $33 \%$ of the isolates had nonCandida albicans (Figure 4). However, in saliva isolates, all samples that were isolated from patients with caries exhibited as mono-species $C$. albicans with the cell morphology was predominantly by the yeast form (Figure 5).

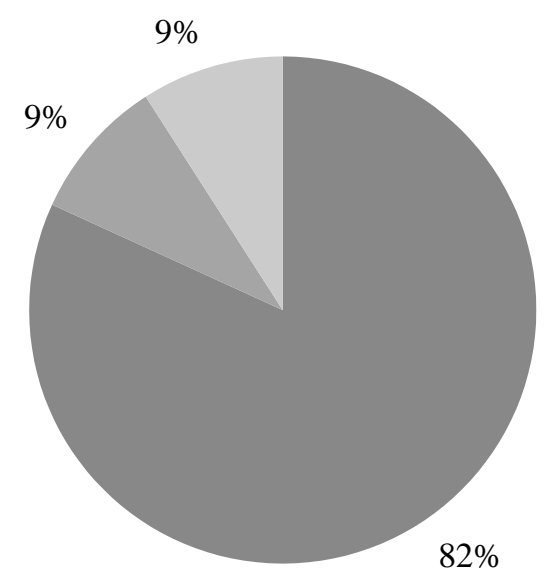

C.alb $\square$ Non-C.alb $\square$ C.alb and Non-C.alb

Figure 3. Percentage of caries children possess $C$. albicans only (C.alb), non- $C$. albicans only (Non-C.alb) or both C. albicans and non-C. albicans (C.alb and Non-C.alb) on the caries tooth surfaces $(\mathrm{N}=15)$.

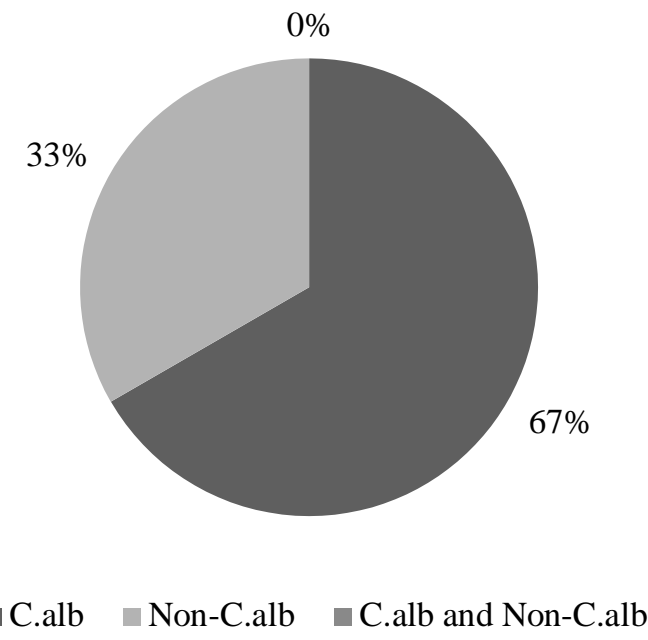

Figure 4. Percentage of caries children with $C$. albicans only (C.alb), non-C. albicans only (non-C.alb) or both C. albicans and non-C. albicans (C.alb and Non-C.alb) isolated from the buccal mucosa of caries patients $(\mathrm{N}=15)$. 


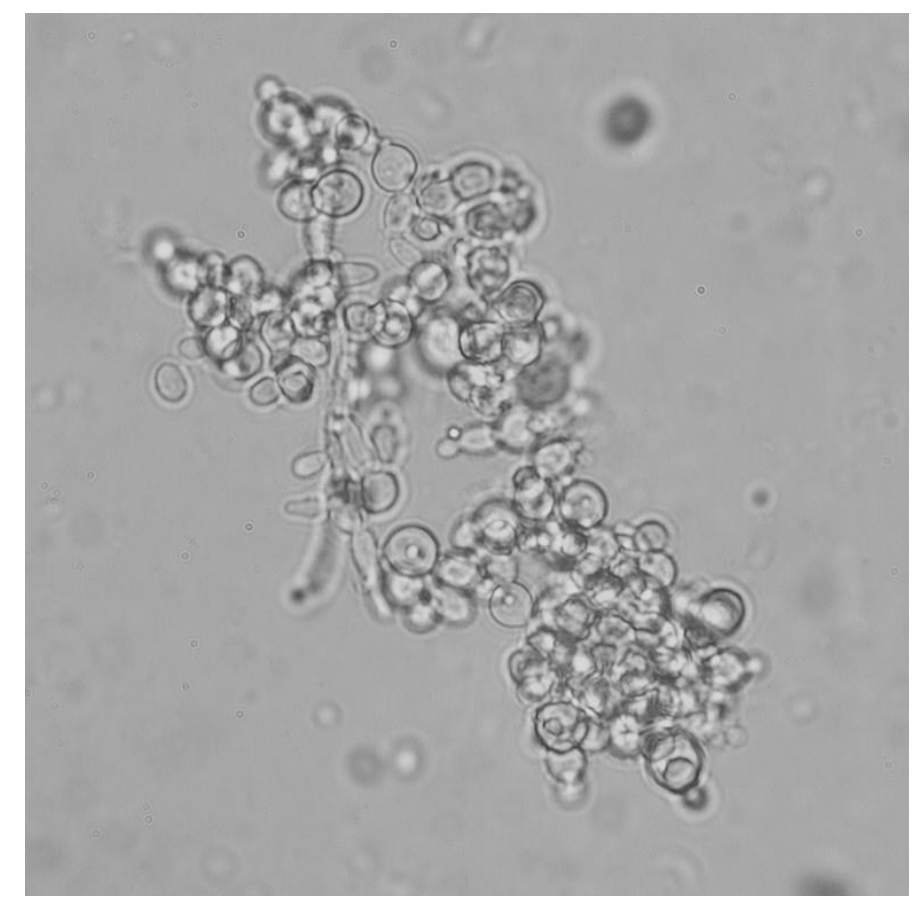

Figure 5. C. albicans isolated from saliva of caries children as observed under light microscope at $1000 x$ magnification.

\section{Colony morphology of Candida species}

All C. albicans isolated from paediatric patients with dental caries exhibited as a circular shape, entire margin and convex elevation. Meanwhile, C. krusei that was isolated exhibited irregular shape, undulate margin and raised elevation. Finally, C. glabrata that were isolated from caries patients exhibited circular shape, entire margin and convex elevation.

\section{Comparison of biofilm formation of $C$. albicans between nano-composites}

C. albicans ATCC 32354 showed adhesion on $\mathrm{CA}, \mathrm{CB}$ and $\mathrm{CC}$ nanocomposites with $4.3 \pm 0.58 \times 10^{3}$ cells $\mathrm{mL}^{-}$ $1,4.3 \pm 0.82 \times 10^{3}$ cells $\mathrm{mL}^{-1}$ and $3.8 \pm$ $1.14 \times 10^{3}$ cells $\mathrm{mL}^{-1}$, respectively. However, there was no significant difference observed between the three nano-composites $(p>0.05)$.

C. albicans HNFC2 exhibited 14.3 $\pm 4.98 \times 10^{3}$ cells $\mathrm{mL}^{-1}$ adhered on $\mathrm{cC}$ nano-composite followed by $\mathrm{CA}$ nanocomposite, which had $9.9 \pm 4.13 \times 10^{3}$ cells $\mathrm{mL}^{-1}$. Besides, there were $7.7 \pm 0.5 \mathrm{x}$ $10^{3}$ cells $\mathrm{mL}^{-1}$ adhered on $\mathrm{cB}$ nanocomposite with a significant difference was observed between $\mathrm{CC}$ and $\mathrm{CB}$ nanocomposites $(P<0.05)$.

Comparison of biofilm formation of $C$. albicans between lab and clinical strains

C. albicans HNFC2 had significantly more cell adhered on the cA nano-composite compared to C. albicans ATCC 32354 ( $p<$ 0.05). This similar trend was also observed in both $\mathrm{CB}$ and $\mathrm{CC}$ nanocomposites. There were $9.9 \pm 4.13 \times 10^{3}$ cells $\mathrm{mL}^{-1}$ of $C$. albicans HNFC2 were adhered on CA nano-composite, which was significantly higher than $C$. albicans ATCC 32354, which exhibited $4.3 \pm 0.58 \mathrm{x}$ $10^{3}$ cells $\mathrm{mL}^{-1}$. There were $7.7 \pm 0.5 \times 10^{3}$ cells $\mathrm{mL}^{-1}$ of $C$. albicans HNFC2 cells adhered on $\mathrm{cB}$ nano-composite, which significantly more than the $C$. albicans ATCC 32354 cells that adhered on the same nano-composite which exhibited 4.3 $\pm 0.82 \times 10^{3}$ cells $\mathrm{mL}^{-1}(\mathrm{p}<0.05)$. The 
adhesion of $C$. albicans HNFC2 cells on $\mathrm{cC}$ exhibited $14.30 \pm 4.98 \times 10^{3}$ cells $\mathrm{mL}^{-1}$ which was significantly higher than $C$. albicans ATCC 32354 which exhibited $3.80 \pm 1.14 \times 10^{3}$ cells $\mathrm{mL}^{-1}(p<0.05)$.

\section{Discussion}

Candida spp. was observed to be isolated only from caries patients. This data supported the hypothesis of the present study, which stated that dental caries enhances the colonization of Candida spp. in children with dental caries. Most of the caries research were reported that a high number of Streptococcus mutans, Lactobacillus species, and Scardovia species in children diagnosed with severe early childhood caries (S-ECC) as its presence intensify the presence of these bacteria. Previous in vitro and in vivo studies have shown that the existence of C. albicans can lead to a complex bacterial-fungal interaction and result in the growth of a cariogenic biofilm environment (O'Donnell et al., 2015; Bowen et al., 2017). For example, induction of glucosyltransferase $B$ by $C$. albicans in addition to bacterial accumulation via chemical-metabolic interactions able to promote the growth of S. mutans (Sztajer et al., 2014; Kim et al., 2017). Cross-feeding interaction between $S$. mutans and $C$. albicans heightens their growth further while creating a Gtf activation loop and promotes the development of highly acidified microenvironment which is a suitable environment for acidogenic-aciduric bacteria (Bowen et al., 2017).

Candida spp. was observed to be isolated mostly on the tooth surface and less on the buccal mucosa and saliva suspension. A study has shown that a hard surface in constant colonization of early colonizer of oral biofilm such as $S$. mutans. $S$. salivarius dominates the microbiota in the oral cavity during the early neonate life until the appearance of the teeth (Sachdeo et al., 2008). The eruption of the teeth during the first year of life leads to colonization by $S$. mutans and S. sanguis (Cortelli et al., 2008). Oral biofilm is a structured community of microbes which adheres to oral surfaces and is compressed within extracellular polymeric substances (EPS), formed from multi-microorganisms and environment of the oral cavity (Filoche et al., 2010). The ability to form biofilm on the oral surfaces is one of important virulence factor of Candida spp. in the oral cavity. Colonization of microorganism on hard and soft tissue surfaces is initiated by adhesion of Candida spp, which lead to the formation of an organized microbial community known as biofilm (Hofer, 2016). Formation of biofilm is the first step in the establishment of dental caries. Candida spp. have the ability to coaggregate with other microorganisms. This ability assists the yeast in attaching on the oral surface which is pre-colonised by the early coloniser bacteria such as $S$. mitis, $S$. oralis and $S$. sanguinis attached on the acquired pellicle that can form easily on hard tissue surface (Kiyora et al., 2000). Candida spp. are found to colonize the tooth surface due to formation of the salivary pellicle. Deposition of pellicle on the tooth surface is the start of the formation of the initial plaque layer (Zijnge et al., 2010). This evidence supports the hypothesis of the present study that dental caries enhances the colonization of Candida spp. in children.

Our results also showed that Candida spp. were isolated from buccal mucosa. Candida spp. have been shown to colonize mucosal surfaces (Salerno et al., 2011; Hofer, 2016). The oral cavity presents abundant surfaces for microbial colonization. Colonization of these surface was started by biofilms of divergent microbial complexity inimitable to each species. While oral biofilm can arise on dental surfaces and mucosal surfaces inside the mouth, the constitution of the microbiomes varies greatly depending on the type of surface (Marsh et al., 2011). The previous study has suggested that 
microbes such as $S$. mutans required hard surfaces for continuous colonization. However, they can also be detected on the soft tissues in low levels (Sachdeo et al., 2008). It has also been shown that $S$. mutans fundamentally disappeared from the oral cavity when all teeth were extracted and reappeared again when the denture was worn. The denture provides a hard surface for colonization (Sachdeo et al., 2008). However, this does not negate the fact that microbes such as $S$. mutans present on the mucosal surface. Candida spp. is known to have the ability to coaggregate with other microorganisms and adhere to the oral surface colonised by the early coloniser bacteria such as $S$. mutans (Kiyora et al., 2000), which can justify the presence of Candida spp. on buccal mucosa.

Candida spp. were also isolated from the saliva suspension. This result was supported by the previous research, which also found Candida spp. such as $C$. albicans aside from other species of microbes in saliva obtained from children (Xiao et al., 2018). Saliva contains proteins such as mucins and statherins, which act as adhesion receptors used by the mannoproteins exist in the Candida spp. Imbalance of normal microbial communities was evident in the condition of decrease or complete absence of saliva in a patient with xerostomia (Salerno et al., 2011). Saliva contains numerous, different proteins and peptides with different molecular mass. The proteomic study revealed over 1050 diverse kinds of proteins in saliva. One of the constituents of the saliva, which is mucins consist of highly glycosylated particles (Silletti et al., 2008). More than a few protein organizations such as MUC5B networks increase the complexity of the saliva structures.

Despite the presence of Candida spp. on several oral surfaces sampled, none were found on the palatal surface. Williams et al. (2011) mentioned that
Candida spp. must present in sufficient amount with an adequate rate of progress to permit their sustained attachment in order for them to colonize a mucosal surface. Thus, Candida biofilms are not typically seen on the palatal mucosa of healthy individuals. However, in cases of commensal carriage, colonization can be detected (Williams et al., 2011).

Our data also showed that the majority of the isolated Candida spp. comprised of $C$. Albicans. Previous clinical studies revealed that compared to other Candida spp. such as $C$. tropicalis, $C$. krusei, and C. glabrata, C. albicans was frequently detected in high numbers in plaque-biofilms from toddlers with early childhood caries (ECC) (de Carvalho et al., 2006; Raja et al., 2010; Yang et al., 2012; Koo et al., 2014). Other Candida spp. such as C. glabrata, C. krusei and $C$. tropicalis were also detected but not as frequent or as abundant as C. albicans (de Carvalho et al., 2006). Harriott and his colleagues also pointed out the capability of C. Albicans as the most dominant fungal pathogen that can cause superficial and systemic infections (Harriott et al., 2011).

Our results have also shown that $C$. albicans attached directly to the surfaces of the restorative materials. Furthermore, C. albicans biofilm was also observed regardless of the type of nano-composite used for both lab and clinical strains. Besides, dental restoration materials have also been shown to induce biofilm formation. The biofilm accumulation of $C$. albicans on nano-composites may cause material surface deterioration, which will further help in the progression of the biofilm formation of different strains of $C$. albicans. C. albicans biofilm was observed to adhere firmly onto the nano-composite beads suggested that none of the nanocomposites exhibited antifungal properties. These findings were similar to the previous study which indicated the 
ability of $C$. Albicans to adhere on various abiotic surfaces including prosthesis, denture base, relining materials and some dental restorative materials (Segal et al., 1988, Waltimo et al., 1999; Maza et al., 2002; Pereira et al., 2007; Lawaf \& Azizi, 2009; Belduz et al., 2017). C. albicans has been reported to form biofilm on various oral surfaces including prosthesis that can lead to oral pathogenesis including oral candidiasis (Akdeniz et al., 2002; Blankenship et al., 2006; Nejad et al., 2013; Sida et al., 2016). The present study showed a significant difference of cell adhesion on the same nanocomposite between lab strain $C$. albicans ATCC 32354 and caries isolate $C$. albicans HNFC2, thus supported the hypothesis of the present study that caries isolate forms more biofilms compared to the lab strain. The previous study has shown that caries-free children had no $C$. albicans. Meanwhile, $82 \%$ of children with caries teeth presented $C$. albicans inside their oral cavity (unpublished data). Furthermore, caries prevalence has been reported to be correlated with the presence of C. Albicans, especially in children, adolescents and young adults (Klinke et al., 2011). Furthermore, the acidic environment can also contribute to the growth of $C$. albicans suggesting that children with caries may possess more $C$. albicans compared to children with a healthy oral condition (Thaweboon et al., 2008).

C. albicans has been shown to adhere on all nano-composites with $\mathrm{cB}$ exhibited the least adhesion by caries isolate C. albicans HNFC2. In contrast, $\mathrm{CC}$ exhibited the most adhered by the yeast strain. These results supported the hypothesis of the present study which $C$. albicans form different cell number in biofilm grown on different nano-composite and that $C$. albicans biofilm formation is nano-composite surface dependent. Each type of dental restorative material and its specific chemistry and their configuration including matrix and fillers arrangement suggested contributing to the different number of $C$. albicans cells adhered on different nano-composites (Beldûz et al., 2016). The adhesion ability of $C$. albicans on dental nano-composite resin materials seems to vary depending on the type of matrix of the nano-composite. Even though all nano-composites that were used in this study were nano-hybrid resin composite type, however, the specific composition has been shown to differ thus affecting the level of $C$. albicans adhesion on the surface of the beads (Table 1 ).

Table 1. Compositions of dental materials

\begin{tabular}{|c|c|c|}
\hline Manufacturer & Type & Compositions \\
\hline$c A$ & $\begin{array}{l}\text { a nano-hybrid composite } \\
\text { with pre-polymerized fillers }\end{array}$ & $\begin{array}{ll}\text { - } & \text { SphereTEC fillers } \\
\text { - } & \text { Non-agglomerated barium glass fillers } \\
\text { - } & \text { Ytterbium fluoride } \\
& \text { Eethacrylic polysiloxane nano-particles }\end{array}$ \\
\hline $\mathrm{cB}$ & $\begin{array}{l}\text { Bulk fill nano-hybrid } \\
\text { composite }\end{array}$ & $\begin{array}{l}\text { - } \text { Fluoro-alumino-silicate glass } \\
\text { - } \text { Bis-GMA } \\
\text { - UDMA Bis-MPEPP } \\
\text { - TEGDMA } \\
\text { - Reaction initiator }\end{array}$ \\
\hline $\mathrm{cC}$ & $\begin{array}{l}\text { a good blend of both } \\
\text { nanotechnology and hybrid } \\
\text { technology }\end{array}$ & $\begin{array}{l}\text { - Strontium glass filler type and high filler } \\
\text { loading } \\
\text { - } \quad \text { Fluorescent agent }\end{array}$ \\
\hline
\end{tabular}




\section{Conclusion}

Dental caries enhances the colonization of Candida spp. in the oral cavity of children and that that caries isolate forms more biofilm on nano-composite compared to the lab strain $C$. albicans thus supported the hypothesis of the study.

\section{Acknowledgement}

This project is funded by International Islamic University Malaysia (P-RIGS18036-0036).

\section{References}

Akdeniz B.G, Koparal E., Sen B.H., Ates M. \& Denizci A.A. (2002) Prevalence of Candida albicans in oral cavities and root canals of children. Journal of Dentistry for Children, 69(3), 289-292.

Alnuaimi A.D., O'Brien-Simpson N.M., Reynolds E.C., McCullough M.J. (2013) Clinical isolates and laboratory reference Candida spesies and strains and have varying abilities to form biofilms. FEMS Yeast Research, 13(7), 689-699.

Arzmi M.H., Abdul Razak F., Yusoff Musa M., Harun W. \& Aznita W.H. (2012) Effect of phenotypic switching on the biological properties and susceptibility to chlorhexidine in Candida krusei ATCC 14243. FEMS Yeast Research, 12(3), 351358.

Arzmi M., Alshwaimi E., Harun W., Razak F.A., Farina F., McCullough M. \& Cirillo N. (2014) Gaining more insight into the determinants of Candida species pathogenicity in the oral cavity. European Journal of Inflammation, 12(2), 227-235.

Arzmi M.H., Alnuaimi A.D., Dashper S., Cirillo N., Reynolds E.C., McCullough M. (2016) Polymicrobial biofilm formation by Candida albicans, Actinomyces naeslundii, and Streptococcus mutans is Candida albicans strain and medium dependent. Medical Mycology, 54(8), 856-864

Arzmi M.H., Cirillo N., Lenzo J.C., Catmull D.V., O'Brien-Simpson N., Eric C. Reynolds E.C., Dashper S.G., McCullough M.J. (2018) mono-species and polymicrobial biofilms differentially regulate the phenotype of genotype-specific oral cancer cells. Carcinogenesis, 40(1), 184-193.

Beldüz N., Kamburoğlu A., Y. Yılmaz, İ. Tosun, M. Beldüz, C. Kara. 2017. Evaluation of Candida albicans biofilm formation on various dental restorative material surfaces. Materials, 20(3), 431-445.

Bowen, W. H., Burne, R. A., Wu, H., \& Koo, H. (2017). Oral biofilms: pathogens, matrix, and polymicrobial interactions in microenvironments.

Trends

in Microbiology, 26(3). 229-242.

Burgers R., Schneider-Brachert W., Rosentritt M., Handel G., Hahnel S. 2009. Candida albicans adhesion to composite resin materials. Clinical Oral Investigations, 13(3), 293-299.

Chaffin W.L. (2008) Candida albicans cell wall proteins. Microbiology \& Molecular Biology Reviews, 72(3), 495-544.

Correa, M.B., Peres M.A., Peres K.G., Horta B.L., Barros A.D., Demarco FF. 2012. amalgam or composite resin? factors influencing the choice of restorative material. Journal of Dentistry, 40(9), 703-710.

Cortelli, J. R., Aquino, D. R., Cortelli, S. C., Nobre Franco, G. C., Fernandes, C. B., RomanTorres, C. V. G., \& Costa, F. O. (2008). Detection of periodontal pathogens in oral mucous membranes of edentulous individuals. Journal Periodontology, 79(10), 1962-1965.

Cramer N.B., Stansbury J.W., Bowman C.N. (2011). Recent advances and developments in composite dental restorative materials." Journal of Dental Research, 90(4), 402416.

de Carvalho, F.G., Silva, D.S., Hebling, J., Spolidorio, L.C. and Spolidorio, D.M. (2006) Presence of mutans Streptococci and Candida spp. in dental plaque/dentine of carious teeth and early childhood caries. Archives of Oral Biology, 51(11), 10241028.

Dewhirst F.E., Chen T., Izard J., Paster B.J., Tanner A.C.R., Yu W.H. \& Wadeb W.G. (2010). The human oral microbiome. Journal of Bacteriology, 192(19), 5002 5017.

Donovan, P. D., Gonzalez, G., Higgins, D. G., Butler, G., \& Ito, K. (2018). Identification of fungi in shotgun metagenomics datasets. PloS one, 13(2): e0192898.

Harriott, M. M., \& Noverr, M. C. (2011). Importance of Candida-bacterial polymicrobial biofilms in disease. TRENDS in Microbiology, 19(11), 557-563.

Hashim, Noor Azlina. 2017. "responsiveness to change of the malay-ecohis following treatment of early childhood caries under general anaesthesia." $P h D$ thesis, University of Malaya.

Haynes, K. (2001). Virulence in Candida species. TRENDS in Microbiology, 9(12), 591-596.

Hofer U (2016) Fungal pathogenesis: candida's toxic relationship with its host. Nature Reviews Microbiology, 14(5), 268-268.

Kim, D., Sengupta, A., Niepa, T. H., Lee, B. H., Weljie, A., Freitas-Blanco, V. S., \& Koo, H. (2017). Candida albicans stimulates Streptococcus mutans microcolony development via cross-kingdom biofilmderived metabolites. Scientific Reports, 7: 41332.

Kiyora, Yusuke \& Toshimasa, N. (2000). Formation of dental plaque-like masses consisting of 
Candida krusei and oral streptococci. Ohu University Dental Journal, 27, 191-198.

Klinke, T., Guggenheim, B., Klimm, W. and Thurrnheer, T. 2011. Dental caries in rats associated with Candida albicans. Caries Research, 45(2), 100-106.

Kolenbrander P.E., Palmer R.J., Periasamy $S$ et al. (2010). Oral multispecies biofilm development and the key role of cell-cell distance. Nature Reviews Microbiology, 8(7), 471-480.

Koo, H., \& Bowen, W. H. (2014). Candida albicans and Streptococcus mutans: A potential synergistic alliance to cause virulent tooth decay in children. Future Microbiology, 9(12), 1295-1297.

Kragelund C., Reibel J. \& Pedersen A.M.L. (2016) Oral candidiasis and the medically compromised patient. Oral Infections and General Health, Springer, 65-77.

Kim J., Sudbery P. 2011. Candida albicans, A major human fungal pathogen. Journal of Microbiology, 49(2), 171-177.

Lackhe, S. A., Joly, S., Daniels, K. \& Soll, D. R. (2002). Phenotype switching and filamentation in Candida glabrata. Microbiology, 148(9), 2661-2674.106

Lalla R.V., Latortue M.C., Hong C.H., et al. (2010). A Systematic review of oral fungal infections in patients receiving cancer therapy. Support Care Cancer 18(8): 98592.

Lawaf S., Azizi A. 2009. Candida albicans adherence to glass ionomer restorative dental materials. Journal of Dental Research, Dental Clinics, Dental Prospects, 3(2), 52-55.

Ma, C., Chen, F., Zhang, Y., Sun, X., Tong, P., Si, Y., \& Zheng, S. (2015). Comparison of oral microbial profiles between children with severe early childhood caries and cariesfree children using the human oral microbe identification microarray. PLoS One, 10(3), $\mathrm{e} 0122075$.

Marsh, P. D., Moter, A., \& Devine, D. A. (2011). Dental plaque biofilms: communities, conflict and control. Journal of Periodontology 2000, 55(1), 16-35.

Martin, D., Persat, F., Piens, M. A., \& Picot, S. (2005). Candida species distribution in bloodstream cultures in lyon, france, 19982001. European Journal of Clinical Microbiology \& Infectection Disease, 24(5), 329-333.

Maza, J.L., Elguezabal, N., Prado, C., Ellacurı', J., Soler, I., and Ponto'n, J. (2002). Candida albicans Adherence to resin-composite restorative dental material: influence of whole human saliva. Oral Surgery Oral Medicine Oral Pathology Oral Radiology \& Endodontology, 94(5), 589-92.

Nejad B.S., Rafiei A. \& Moosanejad F. (2013) Prevalence of Candida species in the oral cavity of patients with periodontitis. African
Journal of Biotechnology, 10(15), 29872990.

Ng, K. P., Madasamy, M., Saw, T. L., Baki, A., He, J. \& Soo-Hoo, T. S. (1999). Candida biotypes isolated from clinical specimens in Malaysia. Mycopathologia, 144(3),135140.

O'Donnell, L. E., Millhouse, E., Sherry, L., Kean, R., Malcolm, J., Nile, C. J., \& Ramage, G. (2015). Polymicrobial Candida Biofilms: friends and foe in the oral cavity. FEMS Yeast Research, 15(7).

Pereira T., Cury A.A., Cenci M.S. Rodrigues-Garcia R.C., (2007). "In vitro Candida colonization on acrylic resins and denture liners: influence of surface free energy, roughness, saliva, and adhering bacteria." International Journal of Prosthodontics, 20(3), 308-310.

Pereira, G. H., Müller, P. R., Szeszs, M. W., Levin, A. S., \& Melhem, M. S. (2010). Five-year evaluation of bloodstream yeast infections in a tertiary hospital: the predominance of non- $C$. albicans Candida Species. Sabouraudia, 48(6), 839-842.

Raja, M., Hannan, A. and Ali, K. (2010) Association of oral candidal carriage with dental caries in children. Caries Research, 44(3), 272276

Ramirez-Garcia A., Arteta B., Abad-Diaz-de-Cerio A., et al. (2013). Candida albicans increases tumor cell adhesion to endothelial cells in vitro: intraspecific differences and importance of the mannose receptor. PLoS One, 8(1), e53584.

Richards, V. P., Alvarez, A. J., Luce, A. R., Bedenbaugh, M., Mitchell, M., Burne, R. A., \& Nascimento, M. M. (2017). The microbiome of site-specific dental plaque of children with different caries status. Infection \& Immunity, 85(8), e00106e00117.

Rybalkin, M. V., Filimonova, N. I., Strilets, O. P. \& Strelnikov, L. S. (2014). The study of protective properties of associated antigens of Candida albicans and Candida tropicalis. Journal of Chemical \& Pharmaceutical Research, 6(4), 954-957.

Sachdeo, A., Haffajee, A. D., \& Socransky, S. S. (2008). Biofilms in the edentulous oral cavity. Journal of Prosthodontics, 17(5), 348356.

Salerno, C., Pascale, M., Contaldo, M., Esposito, V., Busciolano, M., Milillo, L., Guida A, Petruzzi M, Serpico R. (2011). CandidaAssociated denture stomatitis. Medicina Oral Patologia Oral y Cirugia Bucal, 16(2), e139e143.

Samaranayake L.P., K. Cheung L. \& Samaranayake Y.H. (2002) Candidiasis and other fungal diseases of the mouth. Dermatologic Therapy, 15(3), 251-269.

Sida H., Shah P., Pethani J., Patel L. \& Shah H. (2016) Study of biofilm formation as a virulence marker in candida species isolated from various clinical specimens. 
International Journal of Medical Science \& Public Health 2016, 5(5), 842-846.

Silletti, E., Vingerhoeds, M. H., Van Aken, G. A., \& Norde, W. (2008). Rheological behavior of food emulsions mixed with saliva: effect of oil content, salivary protein content, and saliva type. Food Biophysics, 3(3), 318328.

Segal E., Lehrman O., Dayan D. (1988). Adherence in vitro of various Candida Species to acrylic surfaces. Oral Surgery Oral Medicine Oral Pathology, 66(6), 670-673.

Thaweboon S., Thaweboon B., Nakornchai S., Jitmaitree S. (2008). Salivary secretory $\operatorname{lgA}, \mathrm{pH}$, flow rates, Mutans Streptococci and Candida in children with rampant caries. Southeast Asian Journal of Tropical Medicine \& Public Health, 39(5), 893-899.

Sudbery, P. E. (2011). Growth of Candida albicans Hyphae. Nature Reviews Microbiology, 9(10), 737.

Sztajer, H., Szafranski, S. P., Tomasch, J., Reck, M., Nimtz, M., Rohde, M., \& WagnerDöbler, I. (2014). Cross-feeding and interkingdom communication in dualspecies Biofilms of Streptococcus mutans and Candida albicans. ISME Journal, 8(11), 2256.

Waltimo T., Tanner J., Vallittu P., Haapasalo M. 1999. Adherence of Candida albicans to the surface of polymethylmethacrylate-E glass fiber composite used in dentures. International Journal of Prosthodontics, 12(1), 83-86.

Warinner C., Rodrigues J.F.M., Vyas R., Trachsel C., Shved N., Grossmann J., Radini A., Hancock Y., Tito R.Y. \& Fiddyment S. (2014) Pathogens and host immunity in the ancient human oral cavity. Nature Genetics, 46(4), 336-344.

Williams, D. W., Kuriyama, T., Silva, S., Malic, S. \& Lewis, M. A. O. (2011). Candida biofilms and oral Candidosis: treatment and prevention. Periodontology 2000, 55(1), 250-265.

Williams, D., \& Lewis, M. (2011). Pathogenesis and treatment of oral candidosis. Journal of Oral Microbiology, 3(1), 5771.

Xiao, J., Grier, A., Faustoferri, R. C., Alzoubi, S., Gill, A. L., Feng, C., \&amp; Gill, S. R. (2018). Association between Oral Candida and bacteriome in children with severe ECC. Journal of Dental Research, 97(13), 1468-1476

Yang, C. W., Barkham, T. M. S., Chan, F. Y., \& Wang, Y. (2003). Prevalence of Candida Species, including Candida dubliniensis, in Singapore. Journal of Clinical Microbiology, 41(1), 472-474.

Yang, X.Q., Zhang, Q., Lu, L.Y., Yang, R., Liu, Y. and Zou, J. (2012) Genotypic distribution of Candida albicans in dental biofilm of chinese children associated with severe early childhood caries. Archives of Oral Biology, 57(8), 1048-1053.

Zijnge, V., van Leeuwen, M. B. M., Degener, J. E., Abbas, F., Thurnheer, T., Gmür, R., \&
Harmsen, H. J. (2010). Oral biofilm architecture on natural teeth. PloS One, 5(2), e9321.

Zunt, S. L. (2000). Oral candidiasis: diagnosis and treatment. Jounal of Practical Hygiene, 9(5), 31-33. 